Archived version from NCDOCKS Institutional Repository http://libres.uncg.edu/ir/asu/

\title{
Appalachỉan
}

B O O N E, N O R T H C A R O L I N A

\section{Empathic Design As A Framework For Creating Meaningful Experiences}

\author{
By: F. Andres Tellez and Juanita Gonzalez-Tobon
}

\begin{abstract}
This paper introduces empathic design as a framework and a strategy that can be adopted by the emerging field of experience design (XD) to create meaningful experiences connected with people's lives and needs. The paper presents the rationale behind the emergence of empathic design, the traits that characterize this approach to design, a collection of empathic design methods and practices, and a critical discussion of the limitations of empathy in design. Methodologically, this paper is based on a systematic literature review on empathic design, human-centred design, and empathy, which is synthesized and focused its application in experience design. Ultimately, this paper intends to contribute to the broader discussion of how traditional design practices are adapting and evolving to respond to new realities, and how new design paradigms are needed to address the very complex challenges that we face in the 21 st century.
\end{abstract}

Tellez, F. and Gonzalez-Tobon, J. (2019). Empathic Design as a Framework for Creating Meaningful Experiences, Conference Proceedings of the Academy for Design Innovation Management. 2(1), 909-919. 


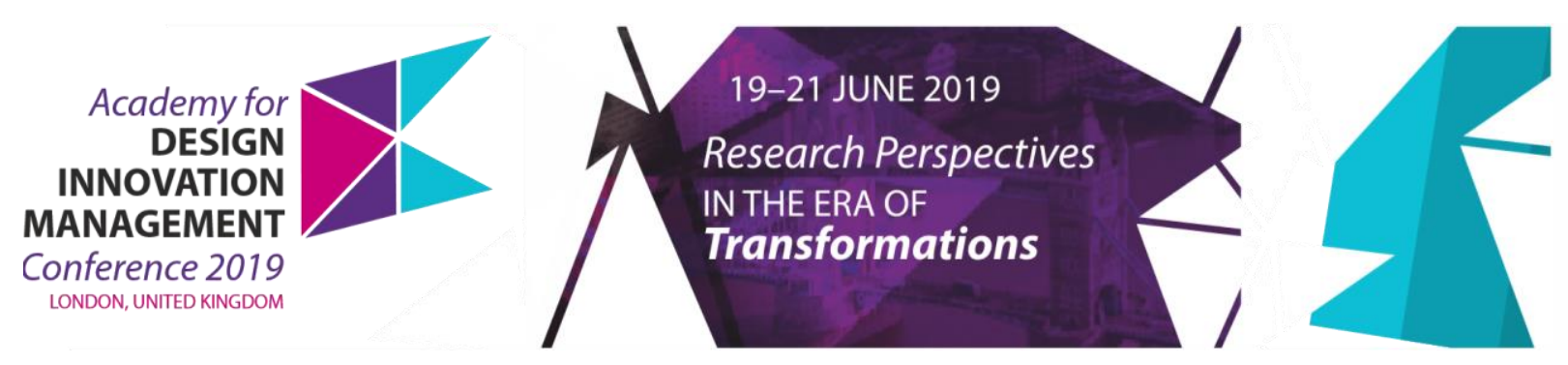

\title{
Empathic Design as a Framework for Creating Meaningful Experiences
}

\author{
TELLEZ F. Andres ${ }^{a *}$ and GONZALEZ-TOBON Juanita ${ }^{b}$ \\ a Universidad Jorge Tadeo Lozano, Colombia \\ b Pontificia Universidad Javeriana, Colombia \\ * corresponding author e-mail: fabioa.tellezb@utadeo.edu.co \\ doi: 10.33114/adim.2019.03.408
}

\begin{abstract}
This paper introduces empathic design as a framework and a strategy that can be adopted by the emerging field of experience design (XD) to create meaningful experiences connected with people's lives and needs. The paper presents the rationale behind the emergence of empathic design, the traits that characterize this approach to design, a collection of empathic design methods and practices, and a critical discussion of the limitations of empathy in design. Methodologically, this paper is based on a systematic literature review on empathic design, human-centred design, and empathy, which is synthesized and focused its application in experience design. Ultimately, this paper intends to contribute to the broader discussion of how traditional design practices are adapting and evolving to respond to new realities, and how new design paradigms are needed to address the very complex challenges that we face in the 21 st century.
\end{abstract}

Keywords: empathic design, experience design, human-centred design, empathy, soft skills

\section{Introduction}

In recent decades, as Western societies move towards a post-industrial era, the scope and focus of design have changed from creating functional and aesthetically pleasing artefacts to tailoring meaningful humancentred experiences. In this new scenario, design is expected to create value by improving, enriching, and helping people make sense of their experience within the built environment, which implies that designers are required to have a profound understanding of users so that they can create meaningful experiences mediated by products, environments, services, and systems (Krippendorff, 2006; Sanders \& Stappers, 2008; Norman, 2014; Davis, 2016).

Whereas in most of the 20th century "hard skills" were appreciated and needed to design new products, messages, and environments, in the post-industrial scenario of the 21st century, the so-called "soft skills" are becoming increasingly important to create experiences that connect meaningfully with people's lives and dreams. Among the broad set of "soft skills," empathy has been gaining attention since the late-1990's when companies realized that they needed a closer and a more sensitive relationship with their customers, which led to the emergence of people-centred approaches to design (Sanders, 2006). This shift has favoured the appearance of design approaches, methods, and techniques that place people at the centre of the process such as user-centred design, human-centred design, participatory design, and empathic design (Liem \& Sanders, 2013; Steen, 2012; IDEO, 2011). 
This paper presents empathic design as a framework and a strategy that can be adopted by the emerging field of experience design (XD) to gain a deeper understanding of the human condition and, consequently, create experiences that meet people's needs, preferences, expectations, and aspirations.

\section{The Seeds of Empathic Design}

As technologies have matured and basic needs have been satisfied in most Western urban environments, the demand for more meaningful experiences has increased (Koskinen and Battarbee, 2003). This increasing demand in the last two decades has motivated a movement toward context-sensitive design (i.e., humancentred design approaches) as a response to the limited perspective that practitioners and organizations used to have about people's lives (Kouprie and Sleeswijk Visser, 2009). These changes marked a transition in how industries and designers conceived their relationships with the people they served, which in turn transformed how they approached, got involved with, and understood these same people (users and stakeholders).

As Sanders points out, "designers have been moving increasingly closer to the future users of what they design" (2008, p. 5), which has impacted design philosophies, values, methods, and practices. In this emerging scenario, roles have changed and evolved. Designers have become explorers of people's realities, and people have become partners and experts of their own experiences (Postma, 2012; Michlewski, 2008). Adopting these new roles has required from designers the development of new skill sets, in which empathy is fundamental as it allows for rationally understanding and emotionally connecting with other people's lives and circumstances (Segal \& Fulton Suri, 1997).

\section{Empathy and Design}

Empathy, the ability to feel and understand other's emotions and circumstances, is considered a fundamental skill for designers to acquire an in-depth understanding of people (i.e., end-users and other stakeholders) so that products, services, environments, systems, and experiences meet human needs, expectations, and aspirations. Likewise, empathy is integral to the design process since it enables practitioners to approach other people's realities and perspectives, to uncover insights, and to develop solutions informed and inspired by people's experiences and behaviour. Additionally, empathy has been described as an ability that promotes "people-centred" innovation, and as a competency that is deemed crucial to dealing with the complex sociotechnical issues that humanity faces in the 21st century (Brown, 2009; Brown \& Katz, 2011; Howe, 2013; IDEO, 2011; d.school, 2010; Plattner et al., 2012; Norman, 2014; Kouprie \& Sleeswijk Visser, 2009; Dandavate et al., 1996; Carroll et al., 2010; Sanders, 2006a).

According to Goldman and colleagues, empathy helps designers to move "beyond [their] egocentric views of the world and no longer design based on their own needs, desires, experiences or preferences" (2012, p. 18). By considering other people's perspectives while keeping their focus on the design problem, designers can uncover users' needs and requirements, identify and balance possible conflicting demands, and design satisfactory solutions that are functional, understandable, usable, and enjoyable (IDEO, 2011; Norman, 2013).

For Thomas and McDonagh, empathy is a critical component in current design approaches, as it allows for the generation of holistic design solutions that address the functional and emotional needs of people. This holistic approach is possible thanks to empathy, which "enables designers to gain intimate insights and understanding into human experiences" $(2013$, p. 3). Likewise, Altay (2014) argues that the practice of human-centred design requires empathy, as it increases designers' awareness of how diverse people interact and experience their social environments. According to the author, this awareness is achieved by interacting with users, sharing their everyday experiences, and inviting them to participate in the design process.

Likewise, some authors argue that empathy is especially crucial in human-centred design when designers have less in common with the populations for which they are designing and when they have little or no experience in the contexts and situations that frame the design problem. For instance, Carmel-Gilfilen and Portillo (2016) suggest that skills associated with empathy like listening, observation, and attention to the human experience are particularly essential in the context of health-care design. Additionally, Lee (2012) highlights the importance of empathy when designing for older adults, as it helps in dislodging designers' preconceptions and prejudices, and build an emotional commitment with them. As stated by Lee, these changes in the designers' mindset can lead to reframing the design problem and proposing more successful design concepts. 
A key player in communicating the importance of empathy in design has been the international design consultancy IDEO. This firm pioneered the use of human-centred design methods and influenced the inception of an empathic approach to design (Battarbee et al., 2014, Mattelmäki, Vaajakallio \& Koskinen, 2013). For instance, in one IDEO's toolkits, empathy is presented as a strategy and an ability that enables design teams to create products, services, and systems that reflect a deep understanding of people's problems and realities (IDEO, 2011). According to this publication, empathy for users emerges when designers use qualitative research methods to uncover insights, evaluate people's response to proposed solutions, and, especially, understand people's behaviour. Building this understanding enables designers to "identify physical, cognitive, social and/or cultural needs that we [designers] can meet through the products, services and experiences we create" (IDEO, 2011, p. 68).

In conclusion, authors agree in considering empathy a fundamental ability in current approaches to design, since it allows designers to transcend their assumptions and egocentrism, get immersed into the lives of users and stakeholders, and uncover their latent needs and expectations. Also, it is instrumental for designers in building an emotional connection and a deep understanding of people's reality, which is of particular importance to design for a diverse range of users in contexts that are new to the design team.

\section{Empathic Design}

Empathic design is a branch of human-centred design that aims at building a cognitive and affective understanding of people (potential users and stakeholders) for the development of concepts, products, services, strategies, and systems. This approach has its roots in design practices that focus on people's daily experiences, emotions, behaviours, and desires (Postma, Zwartkruis-Pelgrim, Daemen, \& Du, 2012; Wright \& McCarthy, 2008; Mattelmäki, Vaajakallio, \& Koskinen, 2013; Battarbee, Fulton Suri, \& Gibbs, 2014).

Empathic design comprises methods and techniques that help design teams to uncover people's latent needs, expectations, aspirations, and preferences. These methods aim at understanding people's emotions and life experiences to inform and inspire the design process. They involve collecting and analyzing data from people's everyday lives through the designer's immersion and direct interaction with potential users and stakeholders to provide a unique perspective based on people's experiences and emotions that enrich and complement the insights uncovered by other methods of inquiry such as market research (Battarbee et al., 2014; Leonard \& Rayport, 1997; Mattelmäki et al., 2013; Fulton Suri, 2003; Postma et al., 2012).

\section{Origins and Evolution of Empathic Design}

The first mention of empathic design was in 1991 when Professor Dorothy Leonard-Barton, a researcher on innovation and creativity at Harvard Business School, published "Inanimate Integrators: A Block of Wood Speaks" in the Design Management Journal. This article discussed the use of models and prototypes to foster effective communication in the product development process. Leonard-Barton mentioned empathic design for the first time when discussing strategies to communicate with potential users of those new products and services in development. She presented empathic design as a process of gathering information about potential users to uncover their unrecognized needs and desires (Leonard-Barton, 1991). The author stated that empathic design was inspired by the work of renown industrial designer Henry Dreyfuss, who advocated for an approach to design based on "[direct] experience, observation, and research" (Dreyfuss, 1955, p. 65).

Another important influencer of empathic design was Bill Moggridge, co-founder of the international design consultancy IDEO and former director of the Cooper-Hewitt Design Museum in New York. According to Battarbee and colleagues (2014), in the 1970s Moggridge's studio introduced the observation of people and their context as a method for informing their design work. When Moggridge's studio merged with other firms to form IDEO in 1991, this human-centred approach was adopted by the newly created consultancy (Battarbee et al., 2014). Mattelmäki, Vaajakallio, and Koskinen (2013) also acknowledge the influence of IDEO in the inception of empathic design in the mid- and late-nineties and identify other influencers such as Liz Sanders at SonicRim, Patrick Jordan at Philips, and Dorothy Leonard-Barton at Harvard Business School. Additionally, the authors argue that empathic design originated from the human-centred design community as part of "a larger movement toward context-sensitive design" (Mattelmäki et al., 2013, p. 68).

According to Kouprie and Sleeswijk Visser (2009), this movement was a response to the limited information that current methods offered about the experience, situation, and emotions of users, which in turn limited the designer's capacity to innovate and develop new and successful products. The user-centred perspective 
brought by this movement was embraced by the business community, which saw in these new approaches an opportunity to strengthen the connection with their customers at an emotional level (Postma et al., 2012). Since its emergence, empathic design has evolved and has influenced other approaches to design. Initially, empathic design intended to make sense of the human experience with the purpose to inform and inspire the design process. Later, it involved users more actively through co-design and participatory design methods and recently has been used to foster imagination and explore and build possible alternate futures.

Likewise, empathic design has spread and influenced the work of people working in places such as Aalto University in Finland; TU/Delft, TU/Eindhoven, and Philips in The Netherlands; Carnegie Mellon University, Ohio State University, University of Illinois, IDEO, and SonicRim in the United States; The Hong Kong Polytechnic and Tongji University in China; Politecnico di Milano in Italy; and Universidade Federal do Rio de Janeiro in Brazil (Mattelmäki et al., 2013; Sanders \& Dandavate, 1999; Battarbee et al., 2014; Ho, Ma \& Lee, 2011; Cipolla \& Bartholo, 2014).

\section{Characteristics of Empathic Design}

Empathic design is characterized by proposing a balance between rationality and emotion (Postma et al., 2012). Several authors argue that designing under this framework requires finding equilibrium between the affective involvement of empathizing with another's experience and the cognitive process of analyzing it (Kouprie \& Sleeswijk Visser, 2009; Battarbee et al., 2014). For Postma and colleagues, this balance implies combining "objective observation of people behaviour with more "subjective" interpretations of "what people think, feel and dream" (2012, p. 60). As Fulton Suri points out, "through observation, we become informed, and through empathy, the human connection, we are inspired to imagine new and better possibilities for people" (2003, p. 54).

Another important characteristic of empathic design is the involvement of users and stakeholders as partners in the design process. According to Mattelmäki (2006), such participation requires the designer to develop a sense of respect and commitment to their needs and to build a holistic understanding of their experiences. From an empathic design perspective, users and stakeholders are considered "experts of their experiences and crucial partners in building creative understanding of these experiences" (Postma et al., 2012, p. 60).

Additional to this balanced approach and respectful attitude, empathic design is guided by a set of underlying theoretical and methodological assumptions that Mattelmäki, Vaajakallio, and Koskinen have synthesized in the form of "four key beliefs" (2013, p. 68). These assumptions revolve around the creation of meaning by people, the discovery and interpretation of these meanings by designers, and the nature of the methods used in empathic design. These key beliefs are as follows:

1. People construct meanings that arise and change through interaction with the environment.

2. To explore these meanings, empathic design needs to be done in real life, where these meanings are created and transformed.

3. This meanings exploration should use design-specific methods such as visualization, mockups making, and storyboarding.

4. The research methods used in empathic design are "visual and tactile, inspiration-enhancing, deliberately cheap and low tech, playful, tested in reality, and targeted at the fuzzy front end of the design process" (Mattelmäki, Vaajakallio, \& Koskinen, 2013, p. 69).

\section{Role of the Designer in Empathic Design}

In empathic design, practitioners are expected to have direct interaction with people (users and stakeholders), which means that the designer's role requires getting immersed in the user's world, their lives, and experiences to learn from them and inform and inspire their designs (van Rijn, Sleeswijk Visser, Stappers, \& Özakar, 2011). This immersion also comprises user participation, since they are considered "experts on their experience" (Sleeswijk Visser, Stappers, van der Lugt, \& Sanders, 2005). As a consequence, designers are expected to set the stage for users to participate and to facilitate activities for them to share their expertise with the team (Battarbee et al., 2014, p. 10). However, to maintain a balanced perspective, the user's viewpoint needs to be combined with the designer's personal insights, creativity, vision, and experience (Kouprie \& Sleeswijk Visser, 2009; Postma et al., 2012).

These competencies are part of the skill set that empathic designers require according to several authors. The set is comprised of abilities such as being open-minded, aware of one's context, and self-aware about how one 
thinks and feels. Also, this empathic skill set includes the capacity to observe meticulously, use visual information and tools of visual communication, and switch between empathizing and analyzing modes (Leonard-Barton \& Rayport, 1997; Mattelmäki et al., 2013; Battarbee et al., 2014; Kouprie \& Sleeswijk Visser, 2009).

\section{Empathic Design Methods and Practices}

Perhaps the most transferable aspects of empathic design to experience design (XD) are the methods and practices created or adapted within this approach to design. Most of these methods and techniques are intended to be used during the research phase of the design process, and their primary purpose is to prompt an empathic understanding of other people's experiences (Vaajakallio, 2012).

Empathic design methods are characterized by being user-centred (as they involve users and stakeholders at different extents); visual and tactile (as they provide inspiration and a means of communication to designers); cheap and low-tech (as they are easily and quickly deployed in any context); interpretive (as they are intended to make sense of other people's reality), playful and fun (as they offer opportunities to dream about alternate futures); tested in reality (as they are used to address real-world issues); and targeted at the fuzzy front end (as they are most effective in the early stages of product development) (Koskinen, Mattelmäki, \& Battarbee, 2003).

Even though most methods are focused on the research and concept development stages of the process, Leonard and Rayport (1997) offer an overview of the empathic design process that goes beyond these initial phases. This process is comprised of five steps, namely, (1) observation, (2) capturing data; (3) reflection and analysis; (4) brainstorming for solutions; and (5) developing prototypes of possible solutions. In this model, observation is presented as the preferred method for learning about users on the basis that it allows for uncovering their unarticulated and latent needs.

Kouprie and Sleeswijk Visser (2009) propose a four-phase framework to practice empathy in the design process. This model is based on current literature in psychology and is intended to support designers in implementing empathy in their practice by offering them a guide to approach, interact, and understand users and stakeholders. The four phases proposed by the authors are (1) discovery, in which the designer makes a first contact with the user that raises his curiosity, interest, and motivation; (2) immersion, in which the designer explores the user's world to expand his knowledge and understanding of another's experience; (3) connection, in which the designer connects with the user on an emotional level by recalling his own feelings and experiences; and (4) detachment, in which the designer detaches from his emotional connection with the user to analyse and distil insights from his immersion.

The same authors also propose a system to classify a variety of empathic design methods depending on the purpose and phase of the process in which they can be applied. The categories offered by these authors are as follows: “(1) techniques for direct contact between designers and users (research); (2) techniques for communicating findings of user studies to design teams (communication); and (3) techniques for evoking the designer's own experiences in a domain relevant to the user (ideation)" (Kouprie \& Sleeswijk Visser, 2009; p. 439).

The first category - "techniques for direct contact between designers and users" - includes methods based on user observation (e.g., observing users performing a task at their workplace); designer immersion (e.g., spending the night at the user's home); and generative sessions (e.g., facilitating a session in which users make a collage that captures their experience using public transit) (Kouprie \& Sleeswijk Visser, 2009; IDEO, 2011; Stappers \& Sanders, 2003).

The second category - "techniques for communicating findings of user studies to design teams" - involves methods used when direct contact with users is not possible. This category includes storytelling techniques such as personas (i.e., fictional characters based on user data); scenarios (i.e., fictional situations based on data from users and context); and storyboards (i.e., sequence of images that represent specific situations in the life of a user). Such methods are effective when they "convey the flavour of the user's world, as well as an understanding of it" (Kouprie \& Sleeswijk Visser, 2009, p. 446; Sleeswijk Visser, 2009).

The third and final category - "techniques for evoking the designer's own experiences in a domain relevant to the user" - refers to methods that simulate the user's reality so designers can experience them and adopt their perspective. This category includes role-playing techniques such as product handling (i.e., use of sample products or prototypes by designers); experience prototyping (i.e., simulation of the experience mediated by a 
product or service); bodystorming (i.e., brainstorming that uses body and space); and informance (i.e., informative performance of a situation or behaviour witnessed or researched) (Kouprie \& Sleeswijk Visser, 2009; McDonagh-Philp, 2000; Buchenau \& Fulton Suri, 2000; Moggridge, 2007).

Another classification of empathic design methods is offered by Jane Fulton Suri, Partner Emeritus and Executive Design Director at IDEO, who proposes the following three categories: (1) "looking at what people do," which includes techniques such as observing people in their natural environment, and exposing potential users to prototypes to observe their behaviour; (2) "asking people to participate," which includes techniques that help to reveal people's unarticulated attitudes and thoughts such as drawing, collage-making, storytelling, and diary-keeping; and (3) "trying things ourselves," which includes immersive techniques such as role-playing, experience prototyping, and simulations (Fulton Suri, 2003).

An example of the first category - "looking at what people do" -is the immersion of members of the design team into the users' context, as discussed by IDEO in their human-centred Design Toolkit (2011). This technique aims at providing designers with an experiential understanding of the users' everyday life through an immersive and prolonged exposure to their context and experiences. When using this method, designers spend two to four of days with members of the community of potential users, sharing their daily experiences in the context in which they live, work and socialize. According to IDEO "this kind of deep immersion gives us [designers] informed intuition that we take back with us to design solutions. We begin to take on the perspective of the interview participant which enables us to make design decisions with their perspective in mind" (2011, p. 59). Also, this strategy allows designers to contrast what the potential users say they do, with what they really do, which might not coincide.

An example of the second category - "asking people to participate" -is the use of empathy probes proposed by Mattelmäki and Battarbee (2002). This technique aims at uncovering what people say, do, and make (Sanders, 2002) through self-documentation. The package given to potential users includes a diary, a sheet of stickers (to use on the diary), disposable camera with a list of photos that users need to take (e.g., an object they user every day), and set of cards with questions to be answered depending on the nature of the project. The design team analyzes the information collected by potential users, and later conducts interviews with some of them to validate their preliminary findings. This method helps to promote empathy by providing the design team with a glimpse into the users' reality from their perspective.

An example of the third and last category, "trying things ourselves," is modelling everyday activities as a person with a disability as proposed by Thomas, McDonagh, and Strickfaden (2012). This strategy offers designers the opportunity to undergo the challenges and experiences that a person with a different level of ability encounters every day. An immersive technique is preferred when the presence of the design team into the user's world can be intrusive or when time and resources prevent the team from conducting extensive research with external participants. When using this method, designers execute everyday activities while reducing their specific abilities. For instance, designers can wear devices that limit their range of motion, obstruct their hearing, or restrict their peripheral vision. While they are wearing these devices and executing everyday activities, designers document their experiences in order to reflect on them and present findings to the team in a debriefing session. The purpose of this strategy is to promote empathy with potential users who represent physical disabilities.

Another remarkable example of this third category is offered by industrial designer and gerontologist Pat Moore. In her book Disguised!, Moore (1985) recounts her experience living and traveling for three years prosthetically disguised as an elder woman. This empathic experiment-initiated when Moore was at the age of 26-gave her an immersive experience of an older adult. In an interview conducted by author Roman Krznaric, Moore expressed her intention to gain true empathy with this population through total immersion: "I didn't just want to be an actress pretending to be an elderly person... I wanted a true immersion character, an empathic character, where I could really walk in someone else's shoes" (Krznaric, 2015, loc. 69-70). During this empathic experiment, Moore created different personas to explore the experience of elderly women of diverse health and economic conditions. She visited more than a hundred cities in disguise, and almost lost her life after being attacked by a gang on the streets of New York City (Moore, 1985).

\section{Limitations of Empathic Design}

Empathic design has limitations and is not well suited for addressing every experience design problem. According to Postma and colleagues (2012), this approach is most valuable in the early stages of the design process when opportunities are being identified and new concepts are being proposed. For Koskinen and 
Battarbee (2003), the insights from the user's perspective obtained through empathic design have the most value in the "fuzzy front end" of the process; that is, in the search for new concepts for products, services, strategies, and systems. Sanders reiterates the importance of empathic approaches in these early phases of the development process and highlights that "the action in the fuzzy front end is all about new ways to understand and to empathize with the needs and dreams of people" (Sanders, 2006, p. 1).

Another limitation to empathic design is the risk of running into what has been called the "empathy trap;" that is, focusing only on another's needs while ignoring the designer's own concerns (Stern \& Divecha, 2015). In the case of empathic design, this situation is seen when the design team focuses only on the user experience and loses its drive to find insights that inform and inspire new products and services (Mattelmäki et al., 2013). This situation is often accompanied by the loss of objectivity and a global frame of reference, which occurs when designers establish a strong connection with another person's feelings and perspectives (Fulton Suri, 2003). According to Segal and Fulton Suri (1997), the key to avoiding this trap is to maintain a balanced perspective by combining "loose" empathic strategies with "strict" observation techniques. However, keeping this balance between an empathic and an analytic mindset may be challenging for design teams and individuals. This requires of self-awareness and the capacity to make the switch between these two mindsets (Battarbee et al., 2014).

Another difficulty that empathic design poses to experience design is the uncertainty of the process in its early stages. As the initial phase of the process is devoted to getting immersed into the user's world and does not provide an immediate solution to the posed problem, designers and organizations may not perceive its value at first and may be reluctant to embrace this approach (Kouprie \& Sleeswijk Visser, 2009). For this reason, Kouprie and Sleeswijk Visser highlight the importance of motivation and willingness to pursue an empathic design process. For them, "motivation is crucial for an effective process. When designers do not see the advantages of empathy in design, the results can be unsatisfying" (2009, p. 447).

For design anthropologist Dori Tunstall (2014), the use of empathy in design strategy has serious limitations. Empathy may offer the designer an understanding and/or an emotional connection with people, but it does not necessarily offer a path to take action for others. She proposes that more than having empathy for users and stakeholders, designers should have compassion and design from a position of caring. This approach means for design practitioners to have a "sustained emotional investment in an individual's well being, characterized by a desire to take actions that will benefit that person" (Tunstall, 2014, paragraph 4).

In an op-ed published in AIGA Eye on Design blog, Lilly Smith (2016) questions the use of empathy in the design and business communities. For her, empathy has become a "buzzword" that is being used by companies mostly as a sales pitch. She argues that even if designers use empathy to understand people's needs and create legitimately better products, the purpose is to sell those products. From her perspective, empathy in business and design is less about compassion and more about profit. This viewpoint is summarized by Roman Krznaric, who calls this strategy "empathy marketing" and argues that when businesses apply empathy, they are only "stepping into someone else's shoes to sell them another pair" (as cited in Smith, 2016).

Similarly, Kamil Michlewski, author of the book Design Attitude, differentiates real empathy from that with commercial purposes, which he calls "commercial empathy" (2008, p. 383). He argues that firms such as IDEO have incorporated a light version of practices and methods from anthropology, psychology, and sociology, which fail to offer the same in-depth understanding shown by their academic counterparts. For Michlewski, designers working in these environments "exhibit an attitude that might be described as commercial empathy. That is to say they are sympathetic towards commercially bound reference points of their work" $(2008, \mathrm{p}$. 383).

Even designers who work within this commercial framework recognize that empathy poses its own challenges in the design process. For instance, Steve Selzer, design manager at Airbnb and former creative director at Frog Design, argues that the human-centred design process requires not only a deep understanding of others through empathy but also a deep understanding of oneself (2015). Selzer warns against the "empathy trap" mentioned before, in which designers and researchers centre their attention only on the user's needs while ignoring their own perspectives. He proposes that an alternative to avoid such situations is to acknowledge and understand one's values, perspectives, goals, and biases before trying to understand others through empathy. 
Likewise, Dan Saffer, vice-president of product at Mayfield Robotics and former creative director at Smart Design, claims that empathy is not enough in human-centred design, but it needs to be combined with an objective understanding of the problem, and the informed perspective of the designer (2015). According to Saffer, empathy helps to designers see a problem from the user's perspective, but does not help them to see the solution. For him, empathy is only a stepping stone that helps designers moving from their egocentric perspectives to a real understanding of people and context

In sum, designers have acknowledged the value of empathy in the design process, but there are also voices that warn about the limitations and the pitfalls of using empathy as a design and business strategy. The strongest criticism of this kind of approaches is that they commodify empathy reducing its power to strengthen human relations, as they adopt it as a disposable buzzword to increase sales and profits.

\section{Conclusions}

Based on a systematic literature review, this paper presented and discussed empathic design as a framework and a strategy whose principles, methods, and practices can be adopted and applied by the emerging field of experience design (XD) to create meaningful experiences connected with people's lives and dreams. The paper presented the rationale behind the emergence of empathic design, the traits that characterize this approach to design, a collection of empathic design methods and practices, and a critical discussion of the limitations of empathy in design.

Even though empathic design emerged in a context where digital experiences were not as pervasive as they are today, its principles, practices, and methods can be very well applied to their design, since these are rooted in a profound understanding of people's daily experiences, emotions, behaviours, desires, expectations, and aspirations. It is important, however, to take into consideration the methodological and epistemological limitations of empathic design to avoid running into common pitfalls, such as falling into the "empathy trap," understanding empathy at a "buzzword level," or commodifying empathy to sell things to people instead of addressing their real needs and expectations.

Finally, this paper intends to contribute to the broader discussion of how traditional design practices are adapting and evolving to respond to new realities and scenarios, and how new design paradigms are needed to address the very complex challenges that we face in the 21 st century.

\section{References}

Altay, B. (2014). User-centred design through learner-centred instruction. Teaching in Higher Education, 19(2), 138-155. Retrieved from http://dx.doi.org/10.1080/13562517.2013.827646

Battarbee, K., Fulton Suri, J., \& Gibbs Howard, S. (2014). Empathy on the edge: scaling and sustaining a humancentred approach in the evolving practice of design. Palo Alto, CA. Retrieved from https://www.ideo.com/images/uploads/news/pdfs/Empathy_on_the_Edge.pdf

Brown, T. (2009). Change by Design: How Design Thinking Transforms Organizations and Inspires Innovation. New York, NY: Harper Business.

Brown, T. (2008). Design Thinking. Harvard Business Review, (June), 86-92. Retrieved from http://www.unusualleading.com/wp-content/uploads/2009/12/HBR-on-Design-Thinking.pdf

Buchenau, M., \& Fulton Suri, J. (2000). Experience Prototyping. In Proceedings of the conference on Designing interactive systems processes, practices, methods, and techniques - DIS '00 (pp. 424-433). New York, New York, USA: ACM Press. Retrieved from http://dl.acm.org/citation.cfm?id=347642.347802

Carmel-Giclfilen, C., \& Portillo, M. (2016). Designing with Empathy : Humanizing Narratives for Inspired Healthcare Experiences. Health Environments Research \&Design Journal, 9(2), 130-146. https://doi.org/10.1177/1937586715592633

Carroll, M., Goldman, S., Britos, L., Koh, J., Royalty, A., \& Hornstein, M. (2010). Destination, Imagination and the Fires Within: Design Thinking in a Middle School Classroom. International Journal of Art \& Design Education, 29(1), 37-53. https://doi.org/10.1111/j.1476-8070.2010.01632.x 
Carroll, M., Goldman, S., Britos, L., Koh, J., Royalty, A., \& Hornstein, M. (2010). Destination, Imagination and the Fires Within: Design Thinking in a Middle School Classroom. International Journal of Art \& Design Education, 29(1), 37-53. https://doi.org/10.1111/j.1476-8070.2010.01632.x

Cipolla, C., \& Bartholo, R. (2014). Empathy or Inclusion: A Dialogical Approach to Socially Responsible Design Socially Responsible Design. International Journal of Design, 8(2), 87-100.

D.School. (2010). Bootcamp Bootleg. Retrieved from http://dschool.stanford.edu/use-our-methods/thebootcamp-bootleg/

Design Council. (2007). A Study of the Design Process. Design Council. London, UK. Retrieved from http://www.designcouncil.org.uk/sites/default/files/asset/document/ElevenLessons_Design_Council (2).pdf

Dreyfuss, H. (1955). Designing for people. New York, NY: Simon and Schuster.

Fischer, G. (2002). Beyond "Couch Potatoes": From Consumers to Designers and Active Contributors. First Monday, 7(12). https://doi.org/http://dx.doi.org/10.5210\%2Ffm.v7i12.1010

Fulton Suri, J. (2003). Empathic Design : Informed and inspired by other people's experience. In I. Koskinen, T. Mattelmäki, \& K. Battarbee (Eds.), Empathic Design: User Experience in Product Design (pp. 51-57). Helsinki, Finland: IT Press.

Giacomin, J. (2014). What is human centred design? The Design Journal, 17(4), 606-623. https://doi.org/10.2752/175630614X14056185480186

Goldman, S., Carroll, M., Kabayadondo, Z., Cavagnaro, L. B., Royalty, A. W., Roth, B., ... Kim, J. (2012). Assessing d.learning: Capturing the Journey of Becoming a Design Thinker. In H. Plattner, C. Meinel, \& L. Leifer (Eds.), Design Thinking Research: Measuring Performance in Context (pp. 13-33). Berlin, Germany: Springer Berlin Heidelberg. https://doi.org/10.1007/978-3-642-31991-4

Ho, D. K., Ma, J., \& Lee, Y. (2011). Empathy @ design research: a phenomenological study on young people experiencing participatory design for social inclusion. CoDesign, 7(2), 95-106.

Howe, D. (2013). Empathy: What it is and why it matters. New York: Palgrave McMillan.

IDEO. (2011). Human Centred Design Toolkit (2nd ed.). IDEO.

ISO. (2010). ISO 9241-210:2010 Ergonomics of human-system interaction -- Part 210: Human-centred design for interactive systems. Geneva, Switzerland: International Organization for Standardization.

Jordan, P. W. (2002). Human factors for pleasure seakers. In J. Frascara (Ed.), Design and the Social Sciences: Making Connection (pp. 9-23). London, UK: Taylor \& Francis.

Kolko, J. (2015). Design Thinking Comes of Age. Harvard Business Review, 93(9), 66-71.

Koskinen, I., \& Battarbee, K. (2003). Introduction to User Experience and Empathic Design. In I. Koskinen, T. Mattelmäki, \& K. Battarbee (Eds.), Empathic Design: User Experience in Product Design (pp. 37-50). Helsinki, Finland: IT Press.

Koskinen, I., Mattelmäki, T., \& Battarbee, K. (2003). Empathic Design: User Experience in Product Design. Helsinki, Finland: IT Press.

Kouprie, M., \& Sleeswijk Visser, F. (2009). A framework for empathy in design: stepping into and out of the user's life. Journal of Engineering Design, 20(5), 437-448. https://doi.org/10.1080/09544820902875033

Krippendorff, K. (2006). The Semantic Turn: A New Foundation for Design. Boca Raton, FL: Taylor \& Francis.

Krznaric, R. (2014). Empathy: Why It Matters, and How to Get It [Kindle Ebook]. New York, NY: Penguin.

Kurosu, M. (2011). Human Centred Design. (M. Kurosu, Ed.). London: Springer.

Lee, J.-J. (2012). Against Method: The Portability of Method in Human-Centred Design. Helsinki, Finland: Aalto University.

Leonard-Barton, D. (1991). Inanimate Integrators: A Block of Wood Speaks. Design Management Journal (Former Series), 2(3), 61-67. https://doi.org/10.1111/j.1948-7169.1991.tb00579.x 
Leonard-Barton, D., \& Rayport, J. (1997). Spark innovation through empathic design. Harvard Business Review, (November-December), 102-113. Retrieved from https://blog.itu.dk/MIND-E2010/files/2010/08/sparkinnovation-through-empathic-design1.pdf

Liem, A., \& Sanders, E. B. (2011). The Impact of Human-Centred Design Workshops in Strategic Design Projects. In M. Kurosu (Ed.), Human Centred Design, HCll 2011 (pp. 110-119). London: Springer.

LUMA Institute. (2012). Innovating for people : handbook of human-centred design methods (1st ed.). Pittsburgh, PA: LUMA Institute.

Mattelmäki, T. (2006). Design probes. University of Art and Design Helsinki. Helsinki, Finland: Aalto University.

Mattelmäki, T., \& Battarbee, K. (2002). Empathy probes. In T. Binder, J. Gregory, \& I. Wagner (Eds.), Proceedings of the 7th Biennial Participatory Design Conference (pp. 23-25). Malmo, Sweden: Computer Professionals for Social Responsibility.

Mattelmäki, T., Vaajakallio, K., \& Koskinen, I. (2013). What Happened to Empathic Design? Design Issues, 30(1), 67-77. https://doi.org/10.1162/DESI_a_00249

Mcdonagh-Philp, D. (2000). Undergraduate Design Project Utilising Users as a Design Resource: A Case Study. In S. A. R. Scrivener, L. Ball, \& A. Woodcock (Eds.), Collaborative Design (pp. 493-500). London, UK: Springer.

Michlewski, K. (2008). Uncovering Design Attitude: Inside the Culture of Designers. Organization Studies, 29(03), 373-392. https://doi.org/10.1177/0170840607088019

Moggridge, B. (2007). Designing Interactions. Cambridge, MA: MIT Press.

Moore, P. (1985). Disguised! Waco, TX: Word Books.

Norman, D. A. (2013). The Design of Everyday Things. New York, NY: Basic Books. Retrieved from http://ucdwiki.chuank.com/uploads/Main/UCDReading_wk5.pdf

Norman, D. A. (2014). Why DesignX? Retrieved from http://www.jnd.org/dn.mss/why_designx.html

Pink, D. (2005). A Whole New Mind. New York, NY: Riverhead.

Postma, C. E. (2012). Creating Socionas. TU Delft.

Postma, C., Zwartkruis-Pelgrim, E., Daemen, E., \& Du, J. (2012). Challenges of Doing Empathic Design: Experiences from Industry. International Journal of Design, 6(1), 59-70.

Saffer, D. (2015). In Design, Empathy is Not Enough. Retrieved from https://medium.com/@odannyboy/indesign-empathy-is-not-enough-c315b1c1ecee

Sanders, E. B. (2002). From User-Centred to Participatory Design Approaches. In J. Frascara (Ed.), Design and the social sciences: Making Connections (pp. 1-8). New York: Taylor \& Francis. Retrieved from http://books.google.com/books?hl=en\&lr=\&id=cFW7ULpRjyUC\&oi=fnd\&pg=PA1\&dq=From+UserCentred+to+Participatory+Design+Approaches+Elizabeth\&ots=ttKeXKh4zo\&sig=jtoHsGXSIhI6IGkiELcx6DKJC 7c

Sanders, E. B. (2006). Scaffolds for Building Everyday Cretivity. In J. Frascara (Ed.), Design for Effective Communications: Creating Contexts for Clarity and Meaning (pp. 65-75). New York: Allworth Press.

Sanders, E. B. (2008). An Evolving Map of Design Practice and Design Research. Interactions, XV(6), $13-17$.

Sanders, E. B., \& Stappers, P. J. (2008). Co-creation and the new landscapes of design. CoDesign, 4(1), 5-18. Retrieved from http://www.tandfonline.com/doi/abs/10.1080/15710880701875068

Segal, L. D., \& Fulton Suri, J. (1997). The Empathic Practitioner: Measurements and Intrepretation of User Experience. In Human Factors and Ergonomics in Society (pp. 451-454). https://doi.org/10.1017/CBO9781107415324.004

Selzer, S. (2015). Human-Centred Design: Why Empathy Isn't Everything. Retrieved from https://designmind.frogdesign.com/2015/05/human-centred-design-why-empathy-isnt-everything/

Sleeswijk Visser, F. (2009). Bringing the everyday life of people into design. TU Delft. Retrieved from http://www.narcis.info/publication/RecordID/oai:tudelft.nl:uuid:3360bfaa-dc94-496b-b6f0-6c87b333246c 
Sleeswijk Visser, F., Stappers, P. J., van der Lugt, R., \& Sanders, E. B. (2005). Contextmapping: experiences from practice. CoDesign, 1(2), 119-149. https://doi.org/10.1080/15710880500135987

Smith, L. (2016). Empathy - Honest Design Process or Hollow Sales Pitch ? Retrieved May 5, 2016, from https://eyeondesign.aiga.org/empathy-honest-design-process-or-hollow-sales-pitch/

Steen, M. (2008). The fragility of human-centred design. TU Delft. Retrieved from http://repository.tudelft.nl/assets/uuid:2b930c09-0ad3-41f8-93f0-503eaea04ffo/steen_20081128.pdf

Steen, M. (2012). Human-Centred Design as a Fragile Encounter. Design Issues, 28(1), 72-80. https://doi.org/10.1162/DESI_a_00125

Stern, R., \& Divecha, D. (2015). The Empathy Trap. Psychology Today, 48(3), 31-34.

Thomas, J., \& McDonagh, D. (2013). Empathic design: Research strategies. The Australasian Medical Journal, 6(1), 1-6. https://doi.org/10.4066/AMJ.2013.1575

Thomas, J., McDonagh, D., \& Strickfaden, M. (2012). Empathic Education in Design: Strategies for healthcare practitioners ? Australasian Medical Journal, 5(5), 292-300.

Tunstall, E. D. (2014). Un-designing apathy: Designs for systems of caring. Retrieved from https://theconversation.com/un-designing-apathy-designs-for-systems-of-caring-22866

Vaajakallio, K. (2012). Design games as a tool, a mindset and a structure. Helsinki, Finland: Aalto University.

van Rijn, H., Sleeswijk Visser, F., Stappers, P. J., \& Özakar, A. D. (2011). Achieving empathy with users: the effects of different sources of information. CoDesign, 7(2), 65-77.

https://doi.org/10.1080/15710882.2011.609889

Wright, P., \& McCarthy, J. (2008). Empathy and experience in $\mathrm{HCl}$. In Proceeding of the twenty-sixth annual CHI conference on Human factors in computing systems - CHI'08 (pp. 637-647).

https://doi.org/10.1145/1357054.1357156 